\title{
Formigas (Hymenoptera: Formicidae) como vetores de bactérias em dois hospitais do município de Divinópolis, Estado de Minas Gerais
}

\author{
Ants (Hymenoptera: Formicidae) as vectors for bacteria in two hospitals in the \\ municipality of Divinópolis, State of Minas Gerais
}

\author{
Paula Fernandes dos Santos ${ }^{1}$, Alysson Rodrigo Fonseca ${ }^{1}$ e Newton Moreno Sanches ${ }^{1}$
}

\begin{abstract}
RESUMO
A presença de formigas (Hymenoptera: Formicidae) em ambientes hospitalares pode constituir um problema de saúde pública, especialmente por serem vetores mecânicos de organismos patogênicos. 0 trabalho teve como objetivo realizar o levantamento de formigas e analisar a presença de bactérias a elas associadas em dois hospitais regionais de médio porte da cidade de Divinópolis, MG. As coletas foram realizadas mensalmente, durante um período de seis meses. Foram coletadas formigas Pheidole sp1 e sp2, Linepithema humile, Wasmannia auropunctata, Camponotus sp1 e sp2, Odontomachus sp, Solenopsis sp, Acromyrmex sp e Tapinoma melenocephalum. Observou-se que estas transportavam mecanicamente Pseudomonas aeruginosa, Enterococcus, Streptococcus, Staphylococcus patogênico e não patogênico e Escherichia coli. Tais resultados evidenciam a propensão à ocorrência de infecções hospitalares nesses locais pela transmissão mecânica de agentes patogênicos por formigas.
\end{abstract}

Palavras-chaves: Formigas urbanas. Bactérias. Infecção hospitalar.

\section{ABSTRACT}

The presence of ants (Hymenoptera: Formicidae) in hospital environments may constitute a public health problem, especially since they are mechanical vectors for pathogenic organisms. This study aimed to survey the ant populations and analyze the presence of bacteria associated with them in two medium-sized regional hospitals in the municipality of Divinópolis, Minas Gerais, Brazil. Specimens were collected every monthly over a six-month period. The following ant species were found: Pheidole sp1 and sp2, Linepithema humile, Wasmannia auropunctata, Camponotus sp1 and sp2, Odontomachus sp, Solenopsis sp,Acromyrmex sp and Tapinoma melenocephalum. It was observed that these ants mechanically transported Pseudomonas aeruginosa, Enterococcus, Streptococcus, Escherichia coli and non-pathogenic and pathogenic Staphylococcus. These results show the propensity for occurrences of hospital infections at these sites caused by mechanical transmission of pathogens by ants.

Key-words: Urban ants. Bacteria. Nosocomial infection.

Entre os Artrópodes, os insetos sociais, e particularmente as formigas, estão entre os animais que melhor se adaptaram ao ambiente urbano, apresentando uma maior diversidade nas regiões tropicais. Estima-se que existam cerca de 18.000 espécies de formigas em todo o mundo, sendo no Brasil já catalogadas mais de 2.000 espécies. Poucas espécies de formigas são importantes por causarem problemas ao homem, sendo que apenas $1 \%$ são consideradas pragas e menos de 50 espécies estão adaptadas ao ambiente urbano ${ }^{4}$.

Por apresentarem a capacidade de transportar microrganismos patogênicos, quando ocorrem em hospitais constituem um perigo potencial à saúde pública, podendo essas estar diretamente associadas ao problema de infecção hospitalar ${ }^{2} 36121721$.

1. Centro de Pesquisa, Fundação Educacional de Divinópolis, Universidade do Estado de Minas Gerais, Divinópolis, MG.

Apoio Financeiro: Fundação de Amparo à Pesquisa do Estado de Minas Gerais Endereço para correspondência: Dr. Alysson Rodrigo Fonseca da Silva. Centro de Pesquisa/FUNEDI. Av. Paraná 3001. Jardim Belvedere II, 35501-170 Divinópolis, MG.

Tel: +55 37 3229-3511

e-mail: alysson@funedi.edu.br

Recebido para publicação em 08/05/2009

Aceito em 29/09/2009
A relação entre as formigas e a presença de microrganismos patogênicos foi inicialmente descrita na Inglaterra ${ }^{18}$, na ExChecoslováquia e posteriormente na Alemanha e países do leste europe $\mathrm{u}^{910}$. Na América, foram descritas formigas como vetores de patógenos no Chile ${ }^{13}$, nos Estados Unidos ${ }^{22}$ e no Brasil 7151821.

A diversidade de espécies de formigas encontradas em hospitais brasileiros tem se mantida elevada quando comparada a mirmecofauna, nos mesmos ambientes, em países de clima temperado como nos Estados Unidos ${ }^{22}$ e países da Europa ${ }^{18}$. A erradicação de formigas em prédios urbanos é complexa, especialmente quando considerado o ambiente hospitalar. 0 uso de métodos convencionais, como a aplicação de inseticidas aerossóis e pós-químicos, pode causar danos indesejáveis ao ambiente e às pessoas, podendo ainda acentuar o processo de fragmentação das colônias, levando, em médio prazo, ao aumento do número de ninhos e, conseqüentemente, elevando a população ativa desses organismos ${ }^{3}$.

Numerosos esforços de controle têm sido empregados contra as formigas urbanas, mas a maioria dos resultados tem efeitos temporários. Antes do controle efetivo e determinação das melhores estratégias, é fundamental conhecer a situação 
real da infestação de formigas por monitoramento, assim como a identificação, estudos sobre biologia, comportamento, hábitos alimentares, de nidificação e forrageamento de cada espécie, pois cada uma tem suas características e requer uma estratégia de controle e iscas específicas ${ }^{41123}$.

Tendo em vista a inexistência de estudos dessa natureza na região centro-oeste do Estado de Minas Gerais, assim como a relevância do tema para a saúde pública, o trabalho teve como objetivo realizar o levantamento de formigas nas dependências físicas de dois hospitais regionais de médio porte da cidade de Divinópolis, MG, buscando-se analisar a presença de bactérias a elas associadas.

\section{MATERIAL E MÉTODOS}

Durante o período de seis meses (dezembro de 2006 a maio de 2007), realizaram-se coletas de formigas em dois hospitais de médio porte (relacionados no trabalho como hospitais A e B) localizados no município de Divinópolis, região Centro-Oeste do Estado de Minas

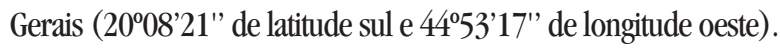

Foram utilizadas iscas não tóxicas compostas por (1) sardinha; (2) mel ebolo sabor de abacaxi, em partes iguais e (3) açúcar de confeiteiro emel na proporção de 1:1, moldada no formato de esfera com diâmetro de $10 \mathrm{~mm}$. As iscas foram acondicionadas em tubos de ensaio de 7,6cm de comprimento e $1,0 \mathrm{~cm}$ de diâmetro, previamente esterilizados por calor úmido a $121^{\circ} \mathrm{C}$ durante 20 minutos.

Nos locais de coleta foram dispostos conjuntos de três tubos de ensaio, sendo um tubo com cada tipo de isca (1, 2 e 3), perfazendo um total de 21 pontos e 63 iscas por coleta, em cada hospital estudado. Dos 21 pontos de coleta, um estava localizado na área externa e os demais na área interna do hospital. As iscas dispostas na área interna foram colocadas na cozinha, cinco quartos, laboratório, capela, almoxarifado, ambulatório, berçário, centro cirúrgico, central de esterilização, clínica médica, dois corredores, farmácia, maternidade, radiologia e unidade de terapia intensiva (UTI). Na área externa, as iscas foram colocadas no jardim.

Foram realizadas coletas diurnas mensais, em que os tubos eram depositados às 12 horas e retirados às 14 horas, totalizando seis coletas, com 21 pontos amostrados em cada coleta, totalizando 378 amostras ao longo do ano. As formigas coletadas foram acondicionadas em frascos com álcool a $70 \%$ e posteriormente identificados no laboratório de Zoologia da Fundação Educacional de Divinópolis, com auxílio das chaves de identificação.

0 isolamento e identificação das bactérias foi realizado transferindo cada formiga para tubo estéril contendo $1 \mathrm{~mL}$ de água peptonada. Uma alíquota de $100 \mathrm{~L}$ de cada tubo foi plaqueada em ágar Müller Hinton e incubada a $37^{\circ} \mathrm{C}$ por $24-48$ horas. As colônias obtidas foram classificadas quanto ao aspecto morfológico e transferidas para tubos com ágar Müller Hinton inclinado.

Após o crescimento, cada isolado foi analisado por coloração de Gram e testado quanto à presença das bactérias Escherichia coli; Pseudomonas aeruginosa; Staphylococcus spp patogênicos e não patogênicos; Streptococcus faecalis e outros Enterococcus sp.
A identificação de Escherichia coli foi realizada plaqueandose as colônias em ágar Mac Conkey e transferindo aquelas com coloração vermelha ou rosada para ágar eosina - azul de metileno. Pseudomonas aeruginosa foram identificadas em ágar cetrimida. Staphylococcus spp patogênicos e não patogênicos foram identificados em ágar manitol-salgado. Todas as placas foram incubadas a $37^{\circ} \mathrm{C}$ por $24-48$ horas.

A avaliação de Streptococcus faecalis e outros Enterococcus sp foi realizada pela técnica de tubos múltiplos utilizando caldo dextrose azida seguido de incubação de alíquotas dos tubos positivos em ágar bile esculina azida e incubada a $35^{\circ} \mathrm{C}$ por $24 \mathrm{~h}$. A confirmação de Streptococcus faecalis foi realizada transferindo as colônias marrons para tubos contendo meio infuso cérebro-coração, com 6,5\% de $\mathrm{NaCl}$ e incubadas a $45^{\circ} \mathrm{C}$ por $24 \mathrm{~h}$.

\section{RESULTADOS}

Foram coletados dez morfoespécies de formigas, sendo: Odontomachus sp, Pheidole sp1 e sp2, Solenopsis sp, Wasmannia auropunctata (Roger, 1863), Tapinoma melanocephalum (Fabricius, 1793), Camponotus sp1 e sp2, Acromyrmex sp e Linepithema bumile (Mayr, 1868).

No hospital A, foram coletadas formigas na área externa, quartos, bloco cirúrgico, corredores e laboratório (Tabela 1). As morfoespécies encontradas foram Camponotus sp1, Pheidole sp1 e sp2, Solenopsis sp, Tapinoma melanocephalum (Fabricius, 1793), Odontomachus sp e Wasmannia auropunctata (Roger, 1863).

No hospital B, foram coletadas formigas na área externa, berçário, quartos, ambulatório, maternidade, clínica médica e lavanderia. As morfoespécies encontradas para estes locais foram Pheidole sp1 e sp2, Acromyrmex sp, Solenopsis sp, Linepithema bumile (Mayr, 1868), Camponotus sp2, Odontomachus sp e Wasmannia auropunctata (Tabela 1). Neste hospital, Tapinoma melanocephalum foi coletada na unidade de terapia intensiva por uma funcionária fora das coletas agendadas.

Observou-se que todas as morfoespécies de formigas coletadas estavam associadas a bactérias, com exceção de Camponotus sp1 (Tabela 1). As bactérias identificadas foram Pseudomonas aeruginosa, Staphylococcus spp patogênico e não-patogênico, Streptococcus faecalis, Streptococcus spp, Escherichia coli e Enterococcus spp.

\section{DISCUSSÃo}

As espécies coletadas apresentaram-se em áreas de risco, como locais de isolamento e bloco cirúrgico, onde os procedimentos são altamente invasivos (Tabela 1). No Hospital B, Tapinoma melanocephalum foi coletada na UTI por uma funcionária, fora das coletas agendadas, contribuindo com os nossos dados e evidenciando que a metodologia adotada pode não ter sido suficiente para identificar todas as espécies existentes nos hospitais avaliados. 


\section{TABELA 1}

Associação entre bactérias e formigas isoladas em diferentes locais em dois hospitais (A e B) no município de Divinópolis, MG.

\begin{tabular}{|c|c|c|}
\hline Formiga & Local de isolamento & Bactérias \\
\hline Acromyrmex sp & $\begin{array}{c}\text { Hospital B } \\
\text { (área externa) }\end{array}$ & $\begin{array}{c}\text { Pseudomonas aeruginosa } \\
\text { Staphylococcus spp patogênico } \\
\text { Streptococcus faecalis }\end{array}$ \\
\hline Camponotus sp1 & $\begin{array}{c}\text { Hospital A } \\
\text { (laboratório) }\end{array}$ & nd \\
\hline Camponotus sp2 & $\begin{array}{c}\text { Hospital B } \\
\text { (área externa) }\end{array}$ & Streptococcus spp \\
\hline Linepithema bumile & $\begin{array}{c}\text { Hospital B } \\
\text { (quartos e ambulatório) }\end{array}$ & $\begin{array}{c}\text { Escherichia coli } \\
\text { Streptococcus spp }\end{array}$ \\
\hline Odontomachus sp & $\begin{array}{l}\text { Hospital B } \\
\text { (berçário) }\end{array}$ & $\begin{array}{c}\text { Pseudomonas aeruginosa } \\
\text { Escherichia coli } \\
\text { Streptococcus spp } \\
\text { Enterococcus spp } \\
\text { Staphylococcus spp patogênico } \\
\text { Staphylococcus spp não patogênico }\end{array}$ \\
\hline Pheidole sp1 e sp2 & $\begin{array}{c}\text { Hospital A } \\
\text { (área externa, corredores e quartos) } \\
\text { Hospital B } \\
\text { (área externa, quartos, lavanderia e maternidade) }\end{array}$ & $\begin{array}{c}\text { Enterococcus spp } \\
\text { Escherichia coli } \\
\text { Pseudomonas aeruginosa } \\
\text { Staphylococcus spp patogênico } \\
\text { Streptococcus spp }\end{array}$ \\
\hline Solenopsis sp & $\begin{array}{c}\text { Hospital A } \\
\text { (área externa e quartos) } \\
\text { Hospital B } \\
\text { (quartos) }\end{array}$ & $\begin{array}{c}\text { Enterococcus spp } \\
\text { Staphylococcus spp não patogênico } \\
\text { Staphylococcus spp patogênico } \\
\text { Streptococcus spp }\end{array}$ \\
\hline Tapinoma melanocephalum & $\begin{array}{c}\text { Hospital A } \\
\text { (bloco cirúrgico) }\end{array}$ & $\begin{array}{c}\text { Enterococcus spp } \\
\text { Staphylococcus spp patogênico } \\
\text { Streptococcus spp }\end{array}$ \\
\hline Wasmannia auropunctata & $\begin{array}{c}\text { Hospital A } \\
\text { (laboratório) } \\
\text { Hospital B } \\
\text { (clínica médica) }\end{array}$ & $\begin{array}{c}\text { Pseudomonas aeruginosa } \\
\text { Staphylococcus spp não patogênico } \\
\text { Staphylococcus spp patogênico } \\
\text { Streptococcus spp }\end{array}$ \\
\hline
\end{tabular}

nd: não determinado.

Representantes do gênero Pheidole apresentaram maior ocorrência nesse estudo (Tabela 1). Segundo Bueno e CamposFarinha ${ }^{5}$, Pheidole e Tapinoma melanocephalum, mesmo como espécies introduzidas, estão entre as formigas mais importantes na maioria das cidades da região sudeste do Brasil. Outro gênero que também se mostrou abundante foi Odontomachus sp, que esteve associado a Pseudomonas aeruginosa e Escherichia coli bem como Staphylococcus spp patogênico e não patogênico, Enterococcus spp e Streptococcus spp.

De acordo com Ritchmann ${ }^{19}$, Pseudomonas aeruginosa tem sido responsável pela maioria das pneumonias hospitalares. Já nos casos de infecção hospitalar e bacteremia, está associada ao cateterismo vesical e venoso central, entubações e neurotropenia grave. Ainda segundo o autor, Pseudomonas aeruginosa tem sido registrada como o segundo agente mais presente nas infecções hospitalares em pacientes queimados.

No que se refere à Escherichia coli, mesmo fazendo parte do trato gastrointestinal dos seres humanos, tem sido reportada como um dos agentes mais importantes das infecções extra-intestinais, como diarréias em adultos e crianças e cerato-conjuntivite experimental, uma infecção semelhante a shigelose ${ }^{14}$. Assim, o problema se mostra relevante nos hospitais estudados, uma vez essa bactéria foi identificada em formigas Odontomachus sp e Pheidole sp1 e sp2 capturadas em áreas com presença de crianças, como berçário e maternidade (Tabela 1).

A análise microbiológica de formigas do gênero Solenopsis sp também apresentou resultados semelhantes com as de Odontomachus sp (Tabela 1), pois ambas estavam associadas a Streptococcus spp, Enterococcus spp, Staphylococcus spp patogênico e não-patogênico.

Outras formigas que estavam carreando Staphylococcus além de Solenopsis sp e Odontomachus sp foram Pheidole sp1 e sp2, Tapinoma melanocephalum, Wasmannia auropunctata e Acromyrmex sp (Tabela 1). A veiculação de Staphylococcus por formigas em ambientes hospitalares evidencia elevado risco, especialmente pelo fato deste microrganismo ser o patógeno que mais comumente causa infecções hospitalares ${ }^{19}$. 
Das formigas que foram identificadas como vetores de Staphylococcus, observou-se que Solenopsis sp, Tapinoma melanocephalum, Pheidole sp1 e sp2 e Odontomachus sp também vetoriavam Enterococcus spp. Essa bactéria é causadora de infecções hospitalares, particularmente em unidades de terapia intensiva. Ela é normalmente encontrada no trato gastrointestinal e é especialmente transmitida em situações de lavagem e manipulação de materiais e falta de assepsia das mãos ${ }^{16}$. 0 gênero Solenopsis já havia sido relatado na literatura como veiculadora dessa bactéria ${ }^{15}$, assim como Tapinoma melanocephalum ${ }^{17}$.

Mesmo em ambiente externo ao hospital, também foi detectada a presença de bactérias patogênicas associadas às formigas Acromyrmex sp (Pseudomonas aeruginosa, Staphylococcus spp patogênico e Streptococcus faecalis), Camponotus sp2 (Streptococcus spp), Pheidole sp1 e sp2 (Enterococcus spp, Escherichia coli, Pseudomonas aeruginosa, Streptococcus spp e Staphylococcus spp patogênico) e Solenopsis sp (Enterococcus spp, Streptococcus spp, Staphylococcus spp não patogênico e patogênico), conforme Tabela 1. No Brasil, não foram encontrados em trabalhos análogos relatos da ocorrência de formigas do gênero Acromyrmex em ambientes hospitalares.

A espécie Tapinoma melanocephalum apresentou uma menor ocorrência, estando presente somente no bloco cirúrgico do hospital A (Tabela 1). Esta espécie, juntamente com Camponotus vittatus, foram identificadas em ambiente hospitalar na Cidade de Uberlândia, MG, no trabalho realizado por Rodovalho $\mathrm{cols}^{20}$.

Camponotus sp1 e sp2 foram encontradas na área externa e quartos e Linepithema humile nos quartos e ambulatório (Tabela 1). Formigas do gênero Camponotus já foram relatadas anteriormente em trabalhos que investigaram sua presença em ambientes hospitalares ${ }^{215}$. De acordo com Bueno e Fowler ${ }^{3}$, em áreas internas de hospitais, a presença desse gênero indicaria deficiências estruturais, as quais, por sua vez, favoreceriam locais para sua nidificação. No presente estudo, Camponotus sp2 apresentou-se associada a Streptococcus, juntamente com as formigas Wasmannia auropunctata, Tapinoma melanocephalum, Acromyrmex sp, Pheidole sp1 e sp2 e Solenopsis sp.

Diante dos fatos, constata-se nos hospitais avaliados, a presença de formigas, assim como sua associação às bactérias patogênicas, evidenciando a relevância do problema na área de saúde pública, especialmente no que se refere à infecção hospitalar. 0 conhecimento sobre a espécie, assim como biologia, ecologia e hábitos das formigas podem auxiliar para que medidas efetivas de controle de surtos de infecção hospitalar possam ser tomadas, bem como o conhecimento sobre as vias de transmissão das bactérias responsáveis por estes surtos. Entretanto, faz-se importante em estudos posteriores correlacionar os achados bacteriológicos com o índice de infecções hospitalares nos locais de coleta, permitindo assim inferir sobre o risco destes vetores como agentes propiciadores de infecções hospitalares.

\section{AGRADECIMENTOS}

À Renata Bernardes Faria Campos, pelo auxílio naidentificação das formigas.

\section{REFERÊNCIAS}

1. Beatson SH. Pharaoh's ants as pathogen vectors in hospital. The Lancet 19: 425$427,1972$.

2. Bicho CL, Brancão MLC, Pires SM. Mirmecofauna (Hymenoptera, Formicidae) em hospitais e postos de saúde no município de Bagé, RS. Arquivos do Instituto Biológico 74: 373-377, 2007.

3. Bueno OC, Campos-Farinha AEC. Formigas Urbanas: comportamento das espécies que invadem as cidades brasileiras. Revista Vetores \& Pragas 2: 13-16, 1998.

4. Bueno OC, Campos-Farinha AEC. As Formigas Domésticas. In: Mariconi FAM (ed). Insetos e outros invasores de residências. Fundação de Estudos Agrários Luiz de Queiroz, Piracicaba, p.135-180, 1999.

5. Bueno OC, Fowler HG. Exotic ants and native ant fauna of Brasilian hospitals. In: Williams DF (ed) Exotic ants: biology, impact and control of introduced species. Westview Studies in Insect Biology, Westview Press, Bolder (Co), p.191-198, 1998.

6. Costa SB, Pelli A, Carvalho GP, Oliveira AG, Silva PR, Teixeira MM, Martins E, Terra APS, Resende EM, Oliveira CCHB, Morais CA. Formigas como vetores mecânicos de microorganismos no Hospital Escola da Universidade Federal do Triângulo Mineiro. Revista da Sociedade Brasileira de Medicina Tropical 39: 527-529, 2006.

7. Costa MJ. Controle de Animais Sinantrópicos (Artrópodes e Roedores). In: Fernandes AT, Fernandes MOV, Filho NR (eds) Infecção Hospitalar e suas implicações na área da saúde. Editora Atheneu, São Paulo, p.1201-1208, 2000 .

8. Edwards JP, Baker LF. Distribution and importance of Pharaoh's ant Monomorium pharaonis (L) in national health service hospitals in England. Journal of Hospital Infection 1: 249-254, 1981.

9. Eichler WD. Die verbreitung der Pharaomeise in Europe. Memorabilia Zoologica 29: 31-40, 1978.

10. Eichler WD. Health aspects and control of Monomorium pharaonis. In: Cedeno A, Jaffé K, Vander Merr RK (eds) Applied Mymercology: a world perspective. Boulder, Westview, p.671-675, 1990.

11. Fowler HG, Bueno OC. Congruent spatial and temporal foraging by a dominant ant (Hym, Formicidae) and its replacement in an assemblage in a large urban structure in southeastern Brazil. Journal of Applied Entomology 120: 29-32, 1996.

12. Fowler HG, Bueno OC, Sadastsune T, Montelli A. Ants as potential vectors of pathogens in hospitals in the state of São Paulo, Brazil. Insect Science and its Applications 14: 367-370, 1993.

13. Ipinza-Regla J, Figuero C, Osorio J. Iridomyrmex huimilis, "hormiga aegentina", como vector de infecciones intrahospitalarias. I. Estudio bacteriologico. Folia Entomologica Mexicana 50: 81-96, 1981.

14. Jawetz E, Melnick J, Adelberg EA. Microbiologia Médica. Editora Guanabara Koogan, Rio de Janeiro, 1998.

15. Lise F, Garcia FRM, Lutinski JA. Association of ants (Hymenoptera: Formicinae) with bacteria hospitals in state of Santa Catarina. Revista da Sociedade Brasileira de Medicina Tropical. 39: 523-526, 2006.

16. Mitak DM, Mitak KW. Dicionário de Bactérias: um guia para o médico. Lilly Laboratórios, 1981

17. Moreira DDO, Morais V, Motta OV, Campos-Farinha AEC, Tonhasca Jr A. Ants as Carriers of Antibiotic-Resistant bacteria in hospitals. Neotropical Entomology 34: 999-1006, 2005.

18. Pereira RS, Ueno M. Formigas como veiculadoras de microrganismos em ambiente hospitalar. Revista da Sociedade Brasileira de Medicina Tropical 41: 492-495, 2008. 
19. Ritchmann R. Guia Prático de Controle de Infecção Hospitalar. Soriak Comércio e Promoções S.A, Eurofarma Laboratórios Ltda, São Paulo, 2005.

20. Rodovalho CM, Santos Al, Marcolino MT, Bonetti AM, BrandeBurgo AM. Urban ants and Transportation of Nosocomial Bacteria. Neotropical Entomology 36: 454-458, 2007

21. Tanaka II, Viggiani AMFS, Person OC. Bactérias veiculadas por formigas em ambiente hospitalar. Arquivos Médicos do ABC 32: 60-63, 2007.
22. Williams DF. Exotic ants: biology, impact and control of introduced species. Westview Press, 1989

23. Zarzuela MFM, Ribeiro MCC, Campos-Farinha AEC. Distribuição de formigas urbanas em um hospital da região sudeste do Brasil. Arquivo do Instituto Biológico 69: 85-87, 2002. 